\title{
Does prophylactic tranexamic acid reduce blood loss in Indian women following vaginal delivery?
}

\author{
Nivedhana Arthi P. ${ }^{1 *}$, Indu N. R. ${ }^{1}$, Jalakandan B. ${ }^{2}$
}

\begin{abstract}
${ }^{1}$ Department of Obstetrics and Gynecology, ${ }^{2}$ Department of Anaesthesiology, Sri Venkateshwaraa Medical College Hospital and Research Centre, Pondicherry, India
\end{abstract}

\author{
Received: 20 December 2020 \\ Revised: 05 January 2021 \\ Accepted: 06 January 2021

\section{*Correspondence:} \\ Dr. Nivedhana Arthi P., \\ E-mail: dr_jalakandan@yahoo.co.in
}

Copyright: () the author(s), publisher and licensee Medip Academy. This is an open-access article distributed under the terms of the Creative Commons Attribution Non-Commercial License, which permits unrestricted non-commercial use, distribution, and reproduction in any medium, provided the original work is properly cited.

\begin{abstract}
Background: Postpartum hemorrhage (PPH) accounts for $25 \%$ to $33 \%$ of obstetric deaths every year. Anemia is a cause and consequence of PPH. Despite intense efforts to prevent anemia, many Indian women labour with low hemoglobin levels. Tranexamic acid (TXA), an antifibrinolytic, have been demonstrated to reduce blood loss and transfusion requirements in various surgeries including cesarean section. Objectives were to study the efficacy of TXA in effectively reducing blood loss in Indian women following vaginal delivery.

Methods: This randomized, double-blind, placebo-controlled study was conducted on 200 patients scheduled for vaginal delivery. In addition to oxytocin 10 units, group T received TXA $15 \mathrm{mg} / \mathrm{kg}$ and group P received normal saline administered over 5 minutes. Estimated blood loss, Hemoglobin deficit, need for additional uterotonics, need for blood transfusion, incidence of PPH and adverse events were noted.

Results: The fall in hemoglobin was significantly higher in group P ( $\mathrm{p}<0.00001)$. Estimated 24 hour blood loss was significantly higher by a mean blood volume of $86.99 \mathrm{ml}$ in group $\mathrm{P}$ compared to group $\mathrm{T}(\mathrm{p}<0.00001)$. The incidence of $\mathrm{PPH}$ was lower in group $\mathrm{T}(2.8 \%$ versus $11.3 \%)$. There were no significant difference in the need for supplementary uterotonics (9.9\% versus $15.5 \%)$ and the incidence of blood transfusion (2.8\% versus $8.5 \%)$. No adverse maternal and fetal outcomes were noted.

Conclusions: To reduce blood loss following vaginal delivery, TXA may be safely recommended as standard adjunct to Oxytocin for regular management of third stage of labour, especially in developing countries like India.
\end{abstract}

Keywords: Postpartum hemorrhage, Anemia, Uterotonics, Tranexamic acid

\section{INTRODUCTION}

Though labour is a physiological process, worldwide about 5,30,000 women die from causes related to pregnancy and childbirth. ${ }^{1}$ Postpartum hemorrhage (PPH) follows 6 to $10 \%$ of all births and accounts for $25 \%$ to $33 \%$ of obstetric deaths every year. ${ }^{1} \mathrm{PPH}$ is commonly defined as blood loss of $\geq 500 \mathrm{ml}$ after vaginal delivery, or $\geq 1000 \mathrm{ml}$ after cesarean section. But these thresholds does not take into account of the pre-existing health status, and blood loss of as little as $200 \mathrm{ml}$ can be life-threatening for a woman with severe anemia or cardiac disease. ${ }^{2}$ According to the national family health survey-III, undertaken in 20052006, more than half of women in India (55\%) have anemia, including $39 \%$ with mild anemia, $15 \%$ with moderate anemia and $2 \%$ with severe anemia. ${ }^{3}$ Despite intense efforts to prevent anemia, many women labour with low hemoglobin $(\mathrm{Hb})$ levels. Anemia is a cause and consequence of PPH. Women with moderate anemia have a $50 \%$ increased risk and those with severe anemia have a tenfold increased risk of $\mathrm{PPH}^{2}{ }^{2}$ Approximately $1 \%$ of women with spontaneous vaginal deliveries require transfusion. ${ }^{4}$ Severe morbidity due to PPH interferes with breastfeeding and bonding. Few develop post-traumatic 
stress disorder. ${ }^{5}$ To control bleeding, some women may need surgery like exploratory laparotomy, uterine artery ligation, brace sutures and at times hysterectomy, thereby removing the possibility of having more children. So there is an immense need to find an effective way to reduce postpartum blood loss, especially in anemic women.

It is essential to prevent PPH in all women, as most of them have low-risk pregnancies with no identifiable risk factors. ${ }^{6}$ As placental expulsion is a critical window for $\mathrm{PPH}$ prevention, various interventions during this stage have been proposed. One involving the mechanical mechanism is the Active management of the third stage of labour by mechanical interventions like preventive administration of uterotonic agents immediately after baby delivery, early cord clamping and cutting, controlled cord traction, and, at times uterine massage. ${ }^{7}$ But the administration of uterotonics, and in particular oxytocin, after delivery is the only intervention that is effective in preventing $\mathrm{PPH}^{7,8}$ In addition to this mechanical enhancement, a complementary biochemical hemostatic effect can be expected from the use of prohemostatic drugs like tranexamic acid (TXA). ${ }^{9}$

The plasma fibrinogen level decreases during the third stage of labour and the level of fibrin degradation products in the serum increases 1 hour after child birth and remains raised in the early puerperium. ${ }^{10,11}$ A close relationship had been observed between reduced fibrinogen levels and PPH outcomes. ${ }^{12}$ Hence, antifibrinolytics will be effective in reducing blood loss by interacting with the fibrinolytic mechanism. ${ }^{11,13}$ TXA exerts its effect by blocking lysine binding sites on plasminogen molecules and thereby inhibits fibrinolysis. ${ }^{14}$ Results from previous trials have revealed that TXA in planned surgery reduces the risk of blood transfusion, mean transfused volume, and need for re-operation due to bleeding, without increasing thrombotic events. ${ }^{15,16}$

The clinical randomisation of an antifibrinolytic in significant haemorrhage (CRASH-2 trial) had demonstrated that the TXA reduces mortality in bleeding trauma patients. ${ }^{17}$ Significant reduction in the mean menstrual blood loss have been reported in menorrhagic women treated with TXA. ${ }^{18}$ This efficacy of TXA in menorrhagia lead to the suggestion that it can reduce uterine blood loss, even of low volume, and in a nonsurgical context. Recently, many randomized controlled trials (RCT) and meta-analyses had suggested that TXA reduces blood loss during both cesarean and vaginal delivery and also reduce bleeding-related mortality among women with PPH, especially when the drug was administered shortly after delivery. ${ }^{19-23}$

As TXA inhibits fibrinolysis, it carries a potential risk of thrombosis. Moreover pregnancy also carries a higher risk of venous thromboembolism, especially during the puerperium. ${ }^{24}$ The World Maternal Antifibrinolytic (WOMAN) trial and the tranexamic acid for preventing postpartum haemorrhage following a vaginal delivery
(TRAAP) trial had assessed the effects of TXA in pregnant women and concluded that TXA significantly reduced bleeding with no major adverse effects. ${ }^{21,23}$ TXA has been shown to be safe for clinical use during pregnancy and breastfeeding and no adverse events in breastfed babies were found in studies. ${ }^{19,23,25,26}$

Many studies had suggested that TXA is a promising drug for the prevention of PPH after vaginal delivery and possibly for the reduction of maternal morbidity related to PPH. ${ }^{14,20,22,27}$ Accordingly, the European society of anaesthesiology recommends administration of TXA in the case of peripartum and postpartum hemorrhage in order to reduce the extent of blood loss, the duration of bleeding and the need for allogeneic blood products (Evidence 1B). ${ }^{28}$ The updated World Health Organization (WHO) recommendation, 2017, recommends early use of intravenous TXA within 3 hours of birth in addition to standard care in all cases of clinically diagnosed PPH, regardless of whether the bleeding is due to genital tract trauma or other causes and this reduces death due to bleeding, with no adverse maternal effects. ${ }^{29}$

Therefore, an attempt was made to translate this positive response of TXA in our Indian women, by administering TXA $15 \mathrm{mg} / \mathrm{kg}$ along with oxytocin, immediately following vaginal delivery. The primary objective of the study was to analyze the efficacy of TXA in reducing blood loss and the secondary objective was to assess its safety and the impact of intervention on the occurrence of $\mathrm{PPH}$ and transfusion requirements.

\section{METHODS}

This randomized, double blinded, placebo controlled study was conducted in 200 pregnant women scheduled for vaginal delivery in our hospital from June 2018 to December 2019. Using sealed envelope technique, they were randomly assigned into two groups: group $\mathrm{T}(\mathrm{n}=100)$ and group $\mathrm{P}(\mathrm{n}=100)$, who along with oxytocin, received tranexamic acid or placebo immediately after delivery.

The eligible participants were full term pregnant women (gestational age $\geq 37$ weeks) aged 18 years or more, primi or second gravida, with singleton pregnancy with cephalic presentation scheduled for vaginal delivery with either spontaneous onset or induced labour. The exclusion criteria were hemoglobin $<8 \mathrm{gm} \%$, uterine scar, severe preeclampsia, macrosomia, polyhydromnios, intrauterine fetal death, abnormal placentation, previous history of $\mathrm{PPH}$, history of thrombosis or epilepsy, history of medical problems involving the heart, liver, kidney and brain, uterine fibroids. Also patients with known hemostatic abnormalities or on anticoagulant therapy, allergy to TXA were also excluded from the study. The written informed consent was obtained from all the patients after explaining the purpose of study.

Detailed history and examination were carried out for all the patients. Heart rate, blood pressure and antenatal 
investigations, especially hemoglobin ( $\mathrm{Hb} \%)$ and hematocrit values performed in the last trimester were recorded. Once the investigator considered that vaginal delivery was likely $(\geq 4 \mathrm{~cm}$ of cervical dilation), randomization and drug preparation was performed by an independent person not related to the study. Both the patients and the investigators were not aware of the group allocation. Labour was monitored carefully using a partogram and augmentation was done whenever required. The patients requiring instrumental or operative delivery were subsequently excluded from the study. For other patients in both the groups, immediately after the delivery of anterior shoulder, 10 units of oxytocin in $500 \mathrm{ml}$ of $5 \%$ dextrose was started intravenously and given over 30 minutes. After cord clamping, group $\mathrm{T}$ patients received $15 \mathrm{mg} / \mathrm{kg}$ tranexamic acid $(100 \mathrm{mg} / \mathrm{ml}$ solution) made to $20 \mathrm{ml}$ with normal saline and Group $\mathrm{P}$ patients received 20 $\mathrm{ml}$ of normal saline intravenously over 5 minutes. An under-buttock disposable drape with graduated plastic collection bag was placed for a minimum of $30 \mathrm{~min}$ or until active bleeding ceased. The practical feasibility of the use of such a bag was demonstrated in the TRACOR trial. ${ }^{7}$

The placenta was delivered by controlled cord traction and rapid suturing of the episiotomy was done. The amount of blood collected was measured. The mops, gauzes, pads, drapes used upto 24 hours post-delivery were weighed by electronic scale (with $1 \mathrm{~g}$ deviation range) before and after blood soaking. Difference in weight was noted. One mg weight was taken as equivalent to $1 \mathrm{ml}$ of blood (gravimetric method).

Amount of blood loss $(\mathrm{ml})=($ weight of soaked gauzes, pads and drapes - dry weight of gauzes, pads and drapes)+amount of blood collected in collection bag.

The heart rate and blood pressure at 15, 30, 60, and 120 minutes after delivery were recorded. Incidence of PPH as defined by blood loss $\geq 500 \mathrm{ml}$, the proportion of women receiving supplementary uterotonics were recorded. Repeat $\mathrm{Hb} \%$ and hematocrit on day two after delivery was performed. The need for iron sucrose injection and blood transfusion were noted. Major side effects of TXA (such as thrombotic events or seizures) were monitored till discharge. Other minor adverse events like nausea, vomiting, diarrhoea, photopsia (sensation of seeing lights, sparks, or flashes of color), and allergy in the delivery room were also noted. Adverse neonatal outcome, if any were also recorded. All the collected data were tabulated and analysed.

\section{Statistical analysis}

Statistical analysis was performed using statistical package for social sciences (SPSS Inc., Chicago, Illinois, USA) version 23. Collected data were expressed as mean \pm standard deviation and percentages. Chi square test was used to compare categorical variables and student's ttest was used for numerical variables and $\mathrm{p}$ value $<0.05$ was considered statistically significant.

\section{RESULTS}

Out of 100 participants in each group, 28 participants from group $\mathrm{T}$ and 29 participants from group $\mathrm{P}$ were excluded because of instrumental and operative delivery and one participant in group $\mathrm{T}$ voluntarily withdrawn, during the study. Finally, 71 participants in each group continued with the study.

The demographic characteristics with regard to age and body mass index were comparable in both the groups. The mean age of participants in group $\mathrm{T}$ and group $\mathrm{P}$ were 25.17 years and 25.38 years respectively. No significant difference were noted in pre-delivery $\mathrm{Hb} \%$ and hematocrit values between both the groups. The duration of third stage of labour was also comparable (Table 1).

Table 1: Patient characteristics.

\begin{tabular}{|c|c|c|c|}
\hline Characteristics & Group T & Group P & $\begin{array}{l}P \\
\text { value }\end{array}$ \\
\hline Age (years)* & $25.17 \pm 3.22$ & $25.38 \pm 2.8$ & $\begin{array}{l}0.34 \\
\text { NS }\end{array}$ \\
\hline BMI $\left(\mathrm{kg} / \mathrm{m}^{2}\right)^{*}$ & $23.91 \pm 2.08$ & $24.39 \pm 2.93$ & $\begin{array}{l}0.13 \\
\text { NS }\end{array}$ \\
\hline $\begin{array}{l}\text { Stage } 3 \text { labour } \\
\text { duration } \\
(\mathrm{min}) *\end{array}$ & $5.07 \pm 0.61$ & $5.16 \pm 0.65$ & $\begin{array}{l}0.2 \\
\text { NS }\end{array}$ \\
\hline $\begin{array}{l}\text { Pre delivery } \\
\text { heart rate } \\
\text { (beats per } \\
\text { minute)* }\end{array}$ & $82.27 \pm 4.06$ & $81.83 \pm 4.55$ & $\begin{array}{l}0.27 \\
\mathrm{NS}\end{array}$ \\
\hline $\begin{array}{l}\text { Pre delivery } \\
\text { systolic blood } \\
\text { pressure } \\
(\mathrm{mmHg})^{*}\end{array}$ & $120.37 \pm 6.90$ & $119.86 \pm 8.17$ & $\begin{array}{l}0.35 \\
\text { NS }\end{array}$ \\
\hline $\begin{array}{l}\text { Pre delivery } \\
\text { diastolic blood } \\
\text { pressure } \\
\text { (mmHg)* }\end{array}$ & $80.24 \pm 6.54$ & $78.99 \pm 6.55$ & $\begin{array}{l}0.13 \\
\text { NS }\end{array}$ \\
\hline $\begin{array}{l}\text { Pre delivery } \\
\text { hemoglobin } \\
(\mathrm{g} / \mathrm{dl})^{*}\end{array}$ & $9.91 \pm 0.89$ & $9.93 \pm 0.91$ & $\begin{array}{l}0.46 \\
\text { NS }\end{array}$ \\
\hline
\end{tabular}

*Data as mean \pm standard deviation, NS - not significant

The pre-delivery heart rate and blood pressure were comparable between both the groups (Table 1). There were statistically significant increase in heart rate following delivery, in both the groups. But the increase in group $\mathrm{T}$ was highly significant during first 15 minutes, after which time, increase in group $\mathrm{P}$ was significantly higher compared to group T (Figure 1).

Both systolic and diastolic blood pressure, followed by an initial significant increase, dropped significantly in both the groups but the decrease was significantly higher in group $\mathrm{P}$ compared to group $\mathrm{T}$ (Figure 2 and 3 ). There was a significant drop in $\mathrm{Hb} \%$ and hematocrit values in both group $\mathrm{T}(1.22 \mathrm{~g} \%, 3.24 \%)$ and group P $(1.57 \mathrm{~g} \%, 4.62 \%)$ 
following delivery. Comparing both the groups, the fall was significantly greater in group $\mathrm{P} \quad(\mathrm{p}<0.00001)$. Accordingly, estimated 24 hour blood loss was significantly higher by a mean blood volume of $86.99 \mathrm{ml}$ in group $\mathrm{P}$ compared to group $\mathrm{T}(\mathrm{p}<0.00001)$ (Table 2).

Table 2: Blood indices and blood loss in both the groups.

\begin{tabular}{|c|c|c|c|c|c|}
\hline S. no. & Characteristics & & Group T & Group P & $P$ value \\
\hline \multirow{2}{*}{1.} & \multirow{2}{*}{ Hemoglobin (g/dl)* } & Pre-delivery & $9.91 \pm 0.89$ & $9.93 \pm 0.91$ & $0.46 \mathrm{NS}$ \\
\hline & & 48 hours post-delivery & $8.69 \pm 0.94$ & $8.36 \pm 1.01$ & $0.024 \mathrm{~S}$ \\
\hline \multirow{2}{*}{2.} & \multirow{2}{*}{ Hematocrit \%* } & Pre-delivery & $29.51 \pm 2.78$ & $29.54 \pm 2.76$ & $0.48 \mathrm{NS}$ \\
\hline & & 48 hours post-delivery & $26.27 \pm 2.89$ & $24.92 \pm 3.06$ & $0.004 \mathrm{~S}$ \\
\hline 3. & \multicolumn{2}{|c|}{ Hemoglobin deficit (g/dl)* } & $1.22 \pm 0.33$ & $1.57 \pm 0.35$ & $<0.00001 \mathrm{~S}$ \\
\hline 4. & \multicolumn{2}{|c|}{ Hematocrit deficit\%* } & $3.24 \pm 1.05$ & $4.62 \pm 1.07$ & $<0.00001 \mathrm{~S}$ \\
\hline 5. & \multicolumn{2}{|c|}{ Estimated blood loss (ml)* } & $311.24 \pm 70.41$ & $398.23 \pm 89.53$ & $<0.00001 \mathrm{~S}$ \\
\hline
\end{tabular}

*Data as mean \pm standard deviation, $\mathrm{S}$-significant, NS-not significant

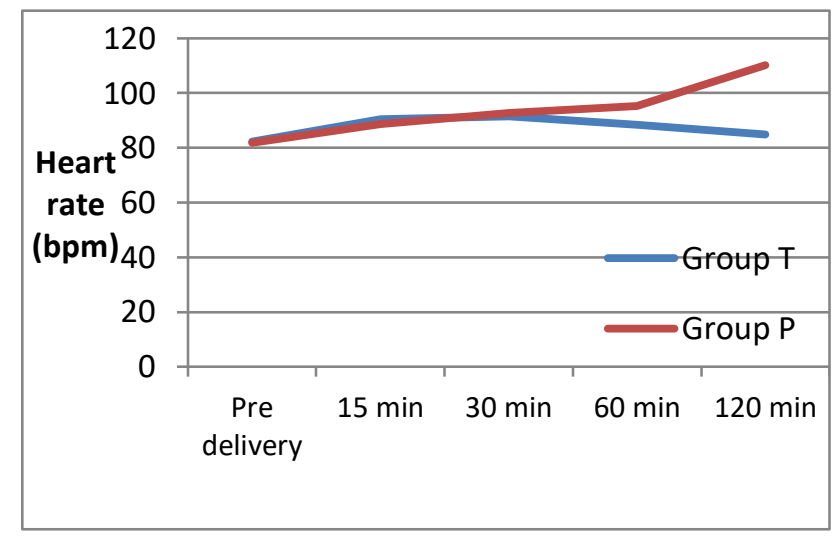

Figure 1: Comparison of heart rate between the groups.

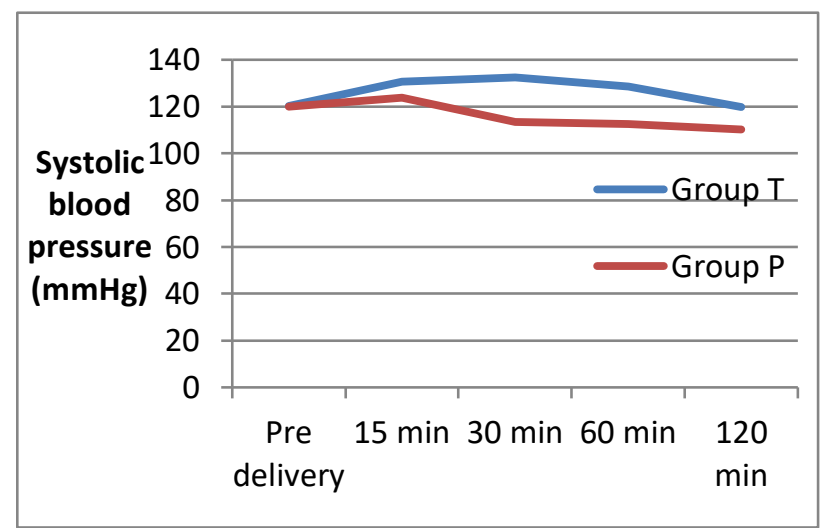

Figure 2: Comparison of systolic blood pressure between the groups.

The incidence of PPH was $2.8 \%$ ( 2 cases) in group $\mathrm{T}$ and $11.3 \%$ ( 8 cases) in group $\mathrm{P}$ and the difference was statistically significant. No significant difference was noted in the need for supplementary uterotonic agents (9.9\% versus $15.5 \%)$. The proportion of patients receiving Iron sucrose injection were also similar. Though the incidence of blood transfusion was higher in group $\mathrm{P}$ $(8.5 \%)$ when compared to group $\mathrm{T}(2.8 \%)$, it was not statistically significant (Table 3).
Table 3: Other secondary outcomes.

\begin{tabular}{|llll|}
\hline Outcomes & $\begin{array}{l}\text { Group T } \\
(\%)\end{array}$ & $\begin{array}{l}\text { Group P } \\
(\%)\end{array}$ & P value \\
\hline $\begin{array}{l}\text { Postpartum } \\
\text { hemorrhage* }\end{array}$ & $2(2.8)$ & $8(11.3)$ & $0.049 \mathrm{~S}$ \\
\hline $\begin{array}{l}\text { Additional } \\
\text { uterotonics* }\end{array}$ & $7(9.9)$ & $11(15.5)$ & $0.31 \mathrm{NS}$ \\
\hline $\begin{array}{l}\text { Iron sucrose } \\
\text { injection* }\end{array}$ & $41(57.8)$ & $43(60.6)$ & $0.73 \mathrm{NS}$ \\
\hline $\begin{array}{l}\text { Blood } \\
\text { transfusion* }\end{array}$ & $2(2.8)$ & $6(8.5)$ & $0.15 \mathrm{NS}$ \\
\hline
\end{tabular}

*Data as number of patients (percentage), S-significant, NS-not significant

None of the patients in both the groups developed any major adverse events, followed till discharge from the hospital.

There was significantly increased incidence of nausea in group $\mathrm{T}$ but the incidence of vomiting and diarrhoea were comparable. No adverse maternal and fetal outcomes were noted (Table 4).

Table 4: Incidence of adverse events.

\begin{tabular}{|llll|}
\hline Adverse events & $\begin{array}{l}\text { Group } \\
\mathrm{T}(\%)\end{array}$ & $\begin{array}{l}\text { Group } \\
\text { P }(\%)\end{array}$ & P value \\
\hline Nausea* & $\begin{array}{l}26 \\
(36.6)\end{array}$ & $12(6.9)$ & $0.008 \mathrm{~S}$ \\
\hline Vomiting* & $5(7.04)$ & $2(2.8)$ & $0.25 \mathrm{NS}$ \\
\hline Diarrhea* & $2(2.8)$ & $1(1.4)$ & $0.56 \mathrm{NS}$ \\
\hline Allergy* & $0(0)$ & $0(0)$ & - \\
\hline $\begin{array}{l}\text { Thromboembolic } \\
\text { phenomena* }\end{array}$ & $0(0)$ & $0(0)$ & - \\
\hline Seizures* & $0(0)$ & $0(0)$ & - \\
\hline $\begin{array}{l}\text { Visual } \\
\text { disturbances* }\end{array}$ & $0(0)$ & $0(0)$ & - \\
\hline $\begin{array}{l}\text { Adverse neonatal } \\
\text { outcomes* }\end{array}$ & $0(0)$ & $0(0)$ & - \\
\hline
\end{tabular}

*Data as number of patients (percentage), S-significant, NS-not significant 


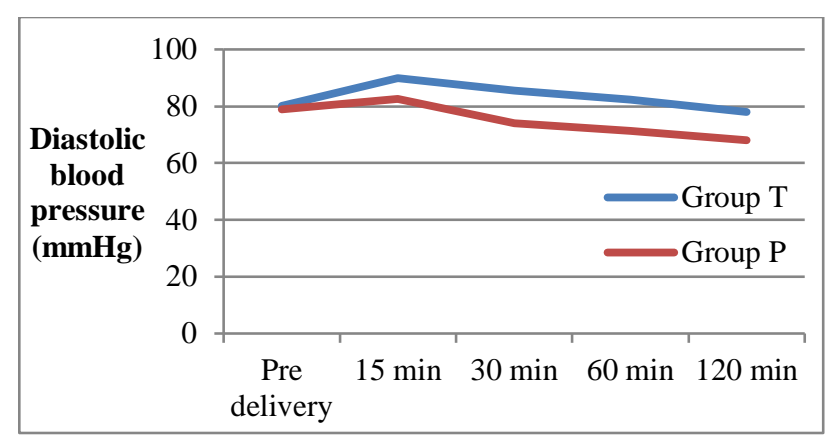

Figure 3: Comparison of diastolic blood pressure between the groups.

\section{DISCUSSION}

WHO defines PPH as blood loss of $500 \mathrm{ml}$ or more. Though loss up to $500 \mathrm{ml}$ at delivery is regarded as 'physiological', a healthy pregnant woman can cope with it without much health effects but in low-resource settings where anemia is prevalent, even a small amount of blood loss can affect an anemic woman adversely. Because of $\mathrm{PPH}$, there is one maternal death every $6 \mathrm{~min}$ somewhere in the world. ${ }^{1}$ Anemia is a cause and consequence of postpartum bleeding. An international survey of 275,000 women revealed that severe maternal outcomes following $\mathrm{PPH}$ were nearly three times more common in anemic women. Indian council for medical research (ICMR) district nutrition survey (1999-2000) had reported prevalence of anemia in pregnancy as $84.2 \%$ with $13.1 \%$ with severe anemia. ${ }^{30}$ So there is a desperate need for measures to reduce postpartum blood loss, especially in anemic women. This in turn by reducing bleeding related maternal morbidity, can contribute for the global commitment to the millennium development goal of reducing maternal deaths by three-quarters by the year 2015 , a commitment that requires a $5.5 \%$ reduction in the maternal mortality rate each year.

The pathophysiology of PPH involves mechanical and clotting mechanism. For mechanical mechanism, prophylactic uterotonics in third stage of labor is used routinely. By using prohemostatic drugs like TXA, a biochemical hemostatic effect can be expected. Extended tissue damage during delivery can cause fibrinolysis and coagulopathy, leading to hemorrhage. TXA reduces the binding of plasminogen and tissue plasminogen activator to fibrin and thereby prevents bleeding by inhibiting the enzymatic breakdown of fibrin blood clots. For several decades, TXA has been used to reduce surgical bleeding in patients undergoing various types of surgery including orthopedic, cardiac, cranial, hepatic, ear, nose and throat and gynecological operations. A systematic review and meta-analysis of 129 trials that included 10,488 surgical patients found that TXA reduced the risk of blood transfusion by over one-third. ${ }^{15} \mathrm{CRASH}-2$ trial had studied the effects of TXA in bleeding trauma patients and concluded that TXA had significantly reduced death due to bleeding with no increase in vascular occlusive events. ${ }^{17}$ The WOMAN trial had evaluated the effect of TXA in
PPH and concluded that TXA had significantly reduced death due to bleeding with no increase in thromboembolic events or complications. ${ }^{23}$ The effect of tranexamic acid on coagulation (ETAC) study, a sub-study within the WOMAN trial, analysed the effects of TXA on fibrinolysis and coagulation during PPH and found that increased fibrinolysis is common in women with PPH and that fibrinolysis is reduced with TXA, as evident by lower Ddimer levels. ${ }^{31}$ Ismail et al in their study, had found that the use of TXA following vaginal delivery increased the resistance in the intramyometrial and subendometrial blood vessels and thereby reduced postpartum blood loss. This effect may be secondary to its antifibrinolytic action. $^{32}$

TXA is a widely used drug with a good safety profile and there is no increased risk of adverse events. ${ }^{17,23,33}$ Because TXA is being given after cutting or clamping the umbilical cord, there will be no risk of placental transfer to the baby. TXA passes into breast milk in very low concentrations, approximately 100th of the concentration in maternal blood and an antifibrinolytic effect in the breast-fed infant, at this concentration is highly unlikely. No adverse events in breastfed babies were found in studies. ${ }^{23,25}$ Potential side-effects of TXA are Commonly: diarrhoea, vomiting and nausea, uncommonly: allergic dermatitis, very rarely: hypersensitivity reactions including anaphylaxis, convulsions, visual disturbances including impaired colour vision, hypotension (generally following an intravenous injection given too rapidly), arterial or venous thrombosis. $^{26}$

In randomised trials of antifibrinolytic agents in surgery, TXA dose regimens vary widely. Many studies on reducing postpartum blood loss have studied TXA at standard dose of 1 g. ${ }^{19,20,34}$ But the standard dose may be overdose for thin mothers and under dose for obese mothers. So we wanted to study the effect of TXA with a dose based on maternal body weight. Goswami et al had compared the efficacy of two different doses of TXA in their study on parturients and inferred that $15 \mathrm{mg} / \mathrm{kg}$ dose was more effective in reducing blood loss than $10 \mathrm{mg} / \mathrm{kg}$ dose, without increase in adverse effects. ${ }^{35}$ The same 15 $\mathrm{mg} / \mathrm{kg}$ dose had been employed in many other studies. ${ }^{36}$ Time is of essence with regard to treating patients with life-threatening bleeding. Urgent treatment is important for two reasons. First, women with PPH bleed to death quickly. Second, TXA is most effective when given early. An individual patient data meta-analysis of the WOMAN and CRASH-2 trials revealed that there was a $10 \%$ reduction in survival benefit for every 15-min delay in treatment with TXA and no significant benefit was noted when there was a delay of more than 3 hours after the event. ${ }^{37}$ Hence in our study, TXA was administered in the dose of $15 \mathrm{mg} / \mathrm{kg}$ body weight, immediately after cord clamping.

The demographic characteristics were comparable in both the groups. The mean age of patients in group $\mathrm{T}$ and group $\mathrm{P}$ were 25.17 years and 25.38 years respectively, in similar 
to the studies by Ferrer et al and Roy et al. ${ }^{22,38}$ Both the groups had similar duration of third stage of labour.

The pre-delivery heart rate and blood pressure were similar in both the groups. There was statistically significant increase in heart rate following delivery, in both the groups which corresponds to the stress and pain of labour and also blood loss. But the increase in group $\mathrm{T}$ was highly significant during first 15 minutes when compared to group $\mathrm{P}$, corresponding to the timing of administration of TXA. After which time, increase in group $\mathrm{P}$ was significantly higher corresponding to the greater blood loss in that group compared to group T. With regard to blood pressure, initially there was significant increase in both the groups, corresponding to the stress and pain of labour. Followed by, there was a decrease in both the groups because of blood loss and the decrease was highly significant in group $\mathrm{P}$ because of greater blood loss in that group. Novikova et al, Sentilhes et al and Roy et al also had observed a similar trend in hemodynamics, in their study on TXA for prevention of blood loss after vaginal delivery. ${ }^{14,21,38}$

There were a significant drop in $\mathrm{Hb} \%$ and hematocrit values in both group $\mathrm{T}(1.22 \mathrm{~g} \%, 3.24 \%)$ and group P (1.57 $\mathrm{g} \%, 4.62 \%)$. The fall was significantly greater in group $\mathrm{P}$ compared to group T. Similar observation were made by Li et al, Gungorduk et al, Saccone et al, Ismail et al, Roy et al and El-Garhy et al. ${ }^{19,20,27,32,38,39}$ Accordingly, the estimated 24 hour blood loss was significantly higher by a mean blood volume of $86.99 \mathrm{ml}$ in group $\mathrm{P}(398.23 \mathrm{ml})$ compared to group $\mathrm{T}(311.24 \mathrm{ml})$. Saccone et al in their metaanalysis including 4671 participants, had evaluated TXA within $10 \mathrm{~min}$ after vaginal delivery and found a significantly lower blood loss with mean difference of $84.74 \mathrm{ml}^{27}$ Ferrer et al had found that the use of TXA significantly reduced mean blood loss by $92 \mathrm{ml}^{22}$ Gungorduk et al and Ismail et al had reported a reduction of mean blood loss by $88.4 \mathrm{ml}$ and $99.5 \mathrm{ml}$ in TXA treated group respectively. ${ }^{20,32}$

Similar to the observation made by Gungorduk et al, Sentilhes et al and Mirghafourvand et al, the need for supplementary uterotonic agents in our study were similar in both the groups $(9.9 \%$ versus $15.5 \%) .{ }^{20,34,40}$ The incidence of PPH was significantly lower in TXA treated group when compared to placebo group (2.8\% versus $11.3 \%)$. Saccone et al, in their metaanalysis found a significantly lower incidence of primary PPH in TXA treated group. ${ }^{27}$ Similar observation were also made by ElGarhy et al and Mirghafourvand et al. ${ }^{39,40}$ Though the incidence of blood transfusion was higher in group $\mathrm{P}$ $(8.5 \%)$ when compared to group $\mathrm{T}(2.8 \%)$, it was not statistically significant. CRASH-2 trial, WOMAN trial, Ismail et al and Sentilhes et al had found no statistically significant difference between the two groups in the incidence of blood transfusion. ${ }^{17,23,32,34}$ The proportion of patients receiving iron sucrose injection were also comparable.
No major adverse effects like thromboembolic events and seizures were noted in both the groups until discharge from the hospital. The increased incidence of nausea was noted in TXA treated group and the incidence of vomiting and diarrhoea were similar in both the groups. No allergy to TXA was reported. No adverse maternal and fetal outcomes were noted. Sentilhes et al in their study found, that nausea and vomiting were significantly more frequent in the TXA group than in the placebo group, but were not severe and there were no significant incidence of thromboembolic events within 3 months after treatment. ${ }^{21}$ Similar observations were made by Yang et al, DuclayBouthors et al, Novikova et al and Esmail El-Garhy et al. $9,13,14,39$

\section{Limitations}

The major limitation was that our study is a small, single centre study with low risk participants. Large, multicentre study involving participants of all risks is needed to evaluate the actual efficacy of TXA. Secondly, the predelivery $\mathrm{Hb} \%$ and hematocrit measurements were performed in the last trimester as part of routine antenatal care, thereby lacked standardized timing. Thirdly, we lacked sufficient power to study the incidence of thromboembolic events. Finally, the duration of follow-up for adverse events were until discharge from hospital. But the risk of adverse events persists through 12 weeks after delivery.

\section{CONCLUSION}

The administration of TXA, along with oxytocin effectively reduces blood loss following vaginal delivery and also decreases the incidence of postpartum hemorrhage without any maternal and neonatal side effects. TXA may be safely recommended as standard adjunct to oxytocin for regular management of third stage of labour, especially in developing countries like India. Further extensive studies are needed to validate our findings.

\section{Funding: No funding sources \\ Conflict of interest: None declared}

Ethical approval: The study was approved by the Institutional Ethics Committee

\section{REFERENCES}

1. Say L, Chou D, Gemmill A, Tunçalp O, Moller AB, Daniels $\mathrm{J}$ et al. Global causes of maternal death: a WHO systematic analysis. Lancet Glob Health. 2014;2(6):323-33.

2. Nair M, Choudhry MK, Choudhry SS, Kakoty SD, Sarma UC, Webster P, et al. on behalf of the IndOSSAssam Steering Committee. Association between maternal anaemia and pregnancy outcomes: a cohort study in Assam, India. BMJ Global Health. 2016;1:000026. 
3. National Family Health Survey (NFHS-III), 2005$2006 . \quad$ Available at: http://www.nfhsindia.org/pdf/India.pdf. Accessed on: 04 February 2014.

4. Ekeroma AJ, Ansari A, Stirrat GM. Blood transfusion in obstetrics and gynaecology. Br J Obstet Gynaecol. 1997;104(3):278-84

5. Thompson JF, Heal LJ, Roberts CL, Ellwood DA. Women's breastfeeding experiences following a significant primary postpartum haemorrhage: a multicentre cohort study. Int Breastfeed J. 2010;5:5.

6. American College of Obstetricians and Gynecologists. Clinical Management Guidelines for Obstetrician-Gynecologists Number 76, October 2006: postpartum hemorrhage. Obstet Gynecol. 2006;108:1039-47.

7. Deneux-Tharaux C, Sentilhes L, Maillard F, Closset E, Vardon D, Lepercq J, et al. Effect of routine controlled cord traction as part of the active management of the third stage of labour on postpartum haemorrhage: multicentre randomised controlled trial (TRACOR). BMJ. 2013;346:1541.

8. Sentilhes L, Merlot B, Madar H, Sztark F, Brun S, Deneux-Tharaux C. Postpartum haemorrhage: prevention and treatment. Expert Rev Hematol. 2016;9:1043-61.

9. Yang $\mathrm{H}$, Zheng S, Shi C. Clinical study on the efficiency of tranexamic acid in reducing postpartum blood loss - a randomized multicentre trial. Zhonghua Fu Chan Zazhi. 2001;36(10):590-2.

10. Hellgren M. Hemostasis during normal pregnancy and puerperium. Semin Thromb Hemost. 2003;29:125-30.

11. Peitsidis P, Kadir RA. Tranexamic acid in pregnancy and postpartum. Expert Opin Pharmacother. 2011;12(4):503-16.

12. Cortet M, Deneux-Tharaux C, Dupont C, Colin C, Rudigoz RC, Bouvier-Colle MH, et al. Association between fibrinogen level and severity of postpartum haemorrhage: secondary analysis of a prospective trial. Br J Anaesth. 2012;108:984-9.

13. Ducloy-Bouthors AS, Jude B, Duhamel A, Broisin F, Huissoud C, Keita-Meyer $\mathrm{H}$, et al. High-dose tranexamic acid reduces blood loss in postpartum haemorrhage. Crit Care Lond Engl. 2011;15:117.

14. Novikova N, Hofmeyr GJ. Tranexamic acid for preventing postpartum haemorrhage. Cochrane Database Syst Rev. 2010;(7):CD007872.

15. Ker K, Edwards P, Perel P, Shakur H, Roberts I. Effect of tranexamic acid on surgical bleeding: systematic review and cumulative meta-analysis. BMJ. 2012;344:3054.

16. Myles PS, Smith JA, Forbes A, et al. Tranexamic acid in patients undergoing coronary-artery surgery. N Engl J Med. 2017;376:136-48.

17. CRASH-2 trial collaborators, Shakur H, Roberts I, Bautista R, Caballero J, Coats T, et al. Effects of tranexamic acid on death, vascular occlusive events, and blood transfusion in trauma patients with significant haemorrhage (CRASH-2): a randomised, placebo-controlled trial. Lancet. 2010;376:23-32.
18. Matteson KA, Rahn DD, Wheeler 2nd TL, Casiano E, Siddiqui NY, Harvie HS, et al. Nonsurgical management of heavy menstrual bleeding: a systematic review. Obstet Gynecol. 2013;121:632-43.

19. Li C, Gong Y, Dong L. Is prophylactic tranexamic acid administration effective and safe for postpartum hemorrhage prevention? A systematic review and meta-analysis. Medicine. 2017;96:5653.

20. Gungorduk K, Asicioglu O, Yildirim G. Can intravenous injection of tranexamic acid be used in routine practice with active management of the third stage of labor in vaginal delivery? A randomized controlled study. Am J Perinatol. 2013;30:407-13.

21. Sentilhes L, Winer N, Azria E. Tranexamic acid for the prevention of blood loss after vaginal delivery. $\mathrm{N}$ Engl J Med. 2018;379:731-42.

22. Ferrer P, Roberts I, Sydenham E. Anti-fibrinolytic agents in post partum haemorrhage: a systematic review. BMC Pregnancy Childbirth. 2009;9:29.

23. WOMAN Trial Collaborators. Effect of early tranexamic acid administration on mortality, hysterectomy, and other morbidities in women with post-partum haemorrhage (WOMAN): an international, randomised, double-blind, placebocontrolled trial. Lancet. 2017;389:2105-16.

24. Galambosi PJ, Gissler M, Kaaja RJ, Ulander VM. Incidence and risk factors of venous thromboembolism during postpartum period: a population-based cohort-study. Acta Obstet Gynecol Scand. 2017;96:852-61.

25. Gilad O, Merlob P, Stahl B, Klinger G. Outcome following tranexamic acid exposure during breastfeeding. Breastfeed Med. 2014;9:407-10.

26. Summary of Product Characteristics for Cyklokapron. Available at: http://www. medicines.org.uk/ emc/medicine/16512/SPC/Cyklokapron+Tablets/. Accessed on: 31 March 2017.

27. Saccone G, Corte L D, D'Alessandro P, Ardino B, Carbone L, Raffone A. Prophylactic use of tranexamic acid after vaginal delivery reduces the risk of primary postpartum hemorrhage. J Matern Fetal Neonatal Med. 2020;33(19):3368-76.

28. Kozek-Langenecker SA, Afshari A, Albaladejo P, Santullano CA, De Robertis E, et al. Management of severe perioperative bleeding: guidelines from the European Society of Anaesthesiology. Eur J Anaesthesiol. 2013;30:270-382.

29. World Health Organization (WHO). Updated WHO Recommendation on Tranexamic Acid for the Treatment of Postpartum Haemorrhage. Geneva, Switzerland: WHO. 2017. Available at: https://www.who.int/reproductivehealth/publications /tranexamic-acid-pph-treatment/en/. Accessed on: 27 September 2020.

30. Toteja G, Singh P. Report of an ICMR Task Force Study-District Nutrition Project. 2001;1.

31. Shakur-Still H, Roberts I, Fawole B, Kuti M, Olayemi OO, Bello A. Effect of tranexamic acid on coagulation and fibrinolysis in women with postpartum haemorrhage (WOMAN-ETAC): a single-centre, 
randomised, double-blind, placebo-controlled trial. Welcome Open Res. 2018;3(100).

32. Ismail AM, Abbas AM, Shahat MA, Ali MK. Evaluation of Subendometrial and Intramyometrial Blood Flow after Intravenous Tranexamic Acid for Prevention of Postpartum Hemorrhage in Vaginal Delivery: A Randomized Controlled Study. J Gynecol Res Obstet. 2017;3(2):46-50.

33. Ker K, Prieto-Merino D, Roberts I. Systematic review, meta-analysis and meta-regression of the effect of tranexamic acid on surgical blood loss. Br $\mathbf{J}$ Surg. 2013;100:1271-9.

34. Sentilhes L, Daniel V, Darsonval A, Deruelle P, Vardon D, Perrotin F, et al. TRAAP - TRAnexamic Acid for Preventing postpartum hemorrhage after vaginal delivery: a multicenter randomized, doubleblind, placebo-controlled trial. BMC Pregnancy Childbirth. 2015;15:135.

35. Goswami U, Sarangi S, Gupta S. Comparative evaluation of two doses of tranexamic acid used prophylactically in anemic parturients for lower segment cesarean section: A double-blind randomized case control prospective trial. Saudi J Anaesth. 2013;7:427.

36. Lundin ES, Johansson T, Zachrisson H, Leandersson U, Backman F, Falknas L, et al. Single-dose tranexamic acid in advanced ovarian cancer surgery reduces blood loss and transfusions: double-blind placebo-controlled randomized multicenter study. Acta Obstet Gynecol Scand. 2014;93(4):335-44.

37. Gayet-Ageron A, Prieto-Merino D, Ker K, Shakur H, Ageron FX, Roberts I. Effect of treatment delay on the effectiveness and safety of antifibrinolytics in acute severe haemorrhage: a meta-analysis of individual patient-level data from 40138 bleeding patients. Lancet. 2017;391:125-32.

38. Roy P, Sujatha MS, Bhandiwad A, Biswas B. Role of Tranexamic Acid in Reducing Blood Loss in Vaginal Delivery. J Obstet Gynecol India. 2016;66(1):246-50.

39. Esmail El-Garhy, Mohamed A H, Elshahat A, et al. Tranexamic acid for prevention of postpartum hemorrhage after vaginal delivery. Egypt J Hospital Med. 2018;73(2):6157-64.

40. Mirghafourvand M, Alizadeh SM, Abasalizadeh F, Shirdel M, et al. The effect of intravenous tranexamic acid on hemoglobin and hematocrit levels after vaginal delivery: a randomized controlled trial. Iranian J Obstet Gynecol Infertil. 2013;16:1-8.

Cite this article as: Nivedhana AP, Indu NR, Jalakandan B. Does prophylactic tranexamic acid reduce blood loss in Indian women following vaginal delivery?. Int J Reprod Contracept Obstet Gynecol 2021;10:497-504. 